\title{
DNA microarray-based detection of antibiotic resistance genes of human isolates of Escherichia coli in Nigeria
}

\author{
Chijioke A. Nsofor $^{1,2 \star}$, Christian U. Iroegbu ${ }^{1}$, Douglas R. Call ${ }^{2}$ and Margaret A. Davies ${ }^{2}$ \\ ${ }^{1}$ Department of Microbiology, University of Nigeria Nsukka, Enugu State, Nigeria. \\ ${ }^{2}$ Department of Veterinary Microbiology and Pathology, Washington State University, Pullman, USA.
}

Accepted 7 September, 2013

\begin{abstract}
Molecular epidemiology of human ecovariants of Escherichia coli from different regions of Nigeria were studied using their antibiotic susceptibility patterns, plasmid profile and DNA microarray techniques. $E$. coli was isolated using Eosin Methylene Blue agar (EMB) and identified by conventional microbiological technique. The isolates were tested against 14 antibiotics using the disc diffusion method. Genotyping was done using DNA microarray. Overall, 42 different antibiotics resistance clusters were observed, with each isolate showing resistance to at least four or more drugs tested. Of the 60 isolates genotyped with DNA microarray, 57 were identified as having, at least, one antimicrobial resistance gene. Among the 90 antibiotic resistance genes detected, bla-CMY-2 was the most prevalent occurring in $38(63.3 \%)$ of the isolates. Other highly prevalent genes occurring in the human isolates, include strA $28(70 \%)$ aadE 28(70\%); TEM1 11(27.5\%); Sul2 14(35\%); and TetA 21(52.5\%). The microarray genotyping corresponded with the phenotype of the strains. Presence of drug-resistance genes/plasmids in commensal strains isolated from apparently healthy individuals is of great public health importance.
\end{abstract}

Key words: DNA microarray, E. coli, Nigeria.

\section{INTRODUCTION}

The large-scale genome sequencing effort and the ability to immobilize thousands of DNA fragments on a surface, such as coated glass slide or membrane, have led to the development of DNA microarray technology (Cassone et al., 2006). An entire microbial genome can be easily represented in a single array, making it feasible to perform genome-wide analysis (Ye et al., 2006) The two common applications of DNA microarray technology in molecular biology are the exploration of genome-wide transcripttional profiles and the measurement of the similarities or differences in genetic contents among different microbes (Peterson et al., 2010). DNA microarray technology is being used to study many bacterial species ranging from standard laboratory strains and pathogens to environmental isolates (Murakami et al., 2002).

DNA microarrays are basically a miniaturized form of dot blot, but in a high-throughput format. There are two major types of DNA microarrays; one is the oligonucleotide-based array and the other is the PCR productbased array (Panicker et al., 2004). A DNA microarray experiment consists of array fabrication, probe preparation, hybridization and data analysis (Call et al., 2001). Although the basic array technology is the same, there are fundamental differences in its application to prokaryotes and eukaryotes.

For example, total RNA is usually labeled for a bacterial 
array experiment, while poly $(\mathrm{A}) \mathrm{RNA}$ is often used for eukaryotic arrays.

Detection of single bacterial genes (antibiotic resistance genes or species-specific genes) in diagnostics and in epidemiological studies is typically carried out by PCR, whereas DNA microarrays have been developed to perform a large number of different hybridization experiments simultaneously on a single membrane or glass substrate. They are well-suited to comprehensively investigate and quantitatively compare the expression levels of a large number of genes, but they can also be easily used in qualitative studies to detect selected DNA sequences (Call et al., 2003a; Call et al., 2003b; Perreten et al., 2005). To better understand the emergence and dissemination of resistance phenotypes from clinical, agricultural, and environmental settings, it is therefore necessary to perform molecular epidemiological analysis of resistant isolates at different levels, comparing whole genomes, single plasmids, and individual resistance gene cassettes. In this study, a method based on DNA microarrays was used to comprehensively assess the presence of antibiotic resistance genes in Nigerian human $E$. coli isolates.

\section{MATERIALS AND METHODS}

\section{Study population}

The study population included humans (who were either ill or presumptively healthy) residing in the five geopolitical zones of Nigeria viz: South-East, South-West, South-South, North-Central and North-North. In the South-South and South-East, clinical specimens were collected at the University of Port Harcourt Teaching Hospital, Port Harcourt, Rivers State and the Abia State University Teaching Hospital, Aba, Abia State respectively. The Lagos State University Teaching Hospital, Ikeja, Lagos was the site of specimen collection for the South-West, while the National Hospital, Abuja and Military Reference Hospital, Kaduna State were the sources of specimens from the North-Central and North-North respectively. All samples from these hospitals were clinical specimens from patients who were having gastroenteritis or similar illness. Apparently healthy undergraduates' students of Madonna University Elele were included in the study for the isolation of human commensal $E$. coli. These individuals reported no exposure to antibiotics for six months prior to sampling and each person received an explanation of the study objectives and consent form for inclusion in the study. All sampling procedures were in accordance with guidelines of the National Health Research Ethics Committee, Nigeria (www.nhrec.net).

\section{Specimen collection, cultivation and identification of $E$. coli}

Sample collection, cultivation, identification of $E$. coli and antibiotics susceptibility testing was based on our previous published work Nsofor and Iroegbu (2013). Briefly, human fecal specimens were streaked directly on EMB agar. No antibiotic was included in the EMB agar plates used for the cultivation. The inoculated plates were incubated overnight at $37^{\circ} \mathrm{C}$. A single colony on EMB with green metallic sheen taken to be $E$. coli was selected from an individual fecal sample for further characterization. E. coli was fully identified using conventional microbiological tests-Indole positive, Methyl red positive and Citrate negative (Cheesbrough, 2000).

\section{Antibiotics susceptibility testing}

The antibiotics susceptibility pattern of the isolates was determined using the disk diffusion method (Cheesbrough, 2000), on MuellerHinton agar (Oxoid, England). Inhibition zone diameter values were interpreted using standard recommendations of the Clinical Laboratory Standard Institute (CLSI, 2006). Susceptibility was tested against ampicillin $(10 \mu \mathrm{g})$, amoxycillin/ clavulanic acid $(20 / 10 \mu \mathrm{g})$, tetracycline $(30 \mu \mathrm{g})$, gentamicin $(10 \mu \mathrm{g})$, cefpodoxime $(10 \mu \mathrm{g})$, Cefoxitin $(30 \mu \mathrm{g})$, cefpirome $(30 \mu \mathrm{g})$, streptomycin $(10 \mu \mathrm{g})$, chloramphenicol $(30 \mu \mathrm{g})$, nalidixic acid $(30 \mu \mathrm{g})$, sulfamethoxazoletrimethoprim $(10 \mu \mathrm{g})$, cephalothin $(30 \mu \mathrm{g})$, nitrofurantoin, ceftriaxone $(30 \mu \mathrm{g})$, and cefotaxine $(30 \mu \mathrm{g})$ (Oxoid, England). E. coli ATCC 25922 was included as a reference strain.

\section{DNA microarray}

The isolates were genotyped using DNA microarray technique (Call et al., 2001). This is based on the principle that nick translated genomic DNA is hybridized to oligonucleotide gene probes printed on a Teflon masked glass slide. The hybridization is detected with florescence marker like the tyramide signal amplification (TSA) system.

\section{Preparation of microarray slides}

Multiple DNA microarrays were printed on glass slides so that independent arrays were contained within ten individual wells defined by Teflon masking slides (Erie Scientific, Portsmouth, N.H. USA); the hydrophobic nature of the masking permitted independent samples to be hybridized within each well. Slides were derivatized with epoxysilane (3-glycidoxypropyltrimethoxysilane; (SigmaAldrich, Milwaukee, WS, USA) as described by Call et al (2001). Prior to printing, the slides were soaked in $2.5 \%$ Contrad 70 detergent (Fisher Scientific, Pittsburgh, PA, USA.) for 2 min, rinsed three times with distilled water, and dried using compressed air. Slides were then soaked for $1 \mathrm{~h}$ in $3 \mathrm{~N} \mathrm{HCl}$, rinsed three times with deionized water, and dried with compressed air.

\section{Construction of DNA microarray}

Oligonucleotide probes of known antibiotics resistance genes were reconstituted in TE buffer diluted to $60 \mu \mathrm{m}$ in print buffer $(0.1 \mathrm{M}$ $\mathrm{Na}_{2} \mathrm{HPO}_{4}, 0.2 \mathrm{M} \mathrm{NaCl}, 0.01 \%$ sodium dodecyl sulfate) with a $\mathrm{pH}$ of 11 and transferred to $384-$ microwell plates for printing. Arbitrary biotinylated oligonucleotides (70-mer; $5 \mu \mathrm{M})$ were included with every array. These biotin pseudoprobes served as positive controls for the detection chemistry and to orient the array for image processing. All probes were deposited as four replicates at a fixed location within each masked well using a Robotic Microgrid II arrayer (Bio-Robotics, Woburn, Mass.USA) with humidity held at $45 \%$. Printing parameters included washing the pins in a recirculating bath (four pins washed twice for $4 \mathrm{~s}$ each time), followed by $0.5 \mathrm{~s}$ of flushing and $6 \mathrm{~s}$ of drying. This washing procedure was repeated twice between probes to minimize possible probe carryover. Printed slides were baked under vacuum $(22 \mathrm{Hg} / \mathrm{mm})$ for $1 \mathrm{~h}\left(130^{\circ} \mathrm{C}\right)$ and stored away from light at room temperature until used.

\section{Genomic DNA extraction}

The bacterial total DNA was extracted using the Qiagen DNeasy silica-gel adsorption method (Qiagen, Valencia, CA USA).

A $1.0-\mathrm{ml}$ volume of overnight broth culture of the test isolate was pelleted in a $1.5 \mathrm{ml}$ microcentrifuge at $10000 \mathrm{rpm}$ for $10 \mathrm{~min}$ and resuspended in $180 \mu \mathrm{l}$ of buffer ATL from the Qiagen DNeasy kit. Then $20 \mu \mathrm{l}$ of Qiagen proteinase K solution was added, mixed by 
vortexing and the cell was incubated for $3 \mathrm{~h}$ in a $55^{\circ} \mathrm{C}$ shaker water bath for lysis. After the lysis, $20 \mu$ of RNase A $(100 \mathrm{~m} \mathrm{~g} / \mathrm{mL})$ (Qiagen, Valencia, CA USA) was added to each tube (to degrade RNA) and the tubes were incubated at room temperature for 2 mim. This was followed by the addition $200 \mu \mathrm{l}$ of buffer AL, vortexing, and incubation at $70^{\circ} \mathrm{C}$ for $10 \mathrm{~min}$. Then, the genomic DNA (gDNA) was concentrated by the addition of $200 \mu \mathrm{l}$ of $100 \%$ ethanol. To separate the DNA from other cellular contaminants, the treated DNA lysate was pipetted into a DNeasy column in a collection tube, and centrifuged for 1 minat $10,000 \times \mathrm{g}$. The remaining contaminants were washed out by using $500 \mu \mathrm{l}$ each of buffer AW1 and AW2 in a new collection tube at each time. The purified gDNA was eluted in a fresh $1.5 \mathrm{ml}$ micro-centrifuge tube by using $200 \mu \mathrm{AE}$ buffer and centrifugation for 1 minat $10,000 \times g$. Finally, the Nanodrop spectrophotometer was used to quantify the DNA. DNA was quantified to properly scale the subsequent nick translation and any sample that failed to reach the value of A260/A280 ratio of 1.7 to 2 or below $25 \mathrm{ng} / \mathrm{\mu l}$ was re-extracted. All the buffers, enzymes and columns used in this extraction came from the Qiagen DNeasy kit (Qiagen, Valencia, CA USA; Cat. No. 69504).

\section{Nick translation: biotinylation and fragmentation of DNA}

This reaction is designed to generate small (50 - 100 base) biotinlabeled DNA probes by nick translation which are important for successful in situ hybridization.

Approximately $1.0 \mu \mathrm{g}$ (up to $40 \mathrm{ul}$ ) of the quantified g DNA, $5 \mu \mathrm{l}$ of $10 X$ dNTP mix [ $0.2 \mathrm{mM}$ each of dCTP, dGTP, dTTP; $0.1 \mathrm{mM}$ of dATP; $0.1 \mathrm{mM}$ of biotin-14-dATP; $500 \mathrm{mM}$ of Tris- $\mathrm{HCl}, \mathrm{pH} 7.8 ; 100$ $\mathrm{mM}$ of $\beta$-mercaptoethanol and $100 \mu \mathrm{g} / \mathrm{ml}$ of nuclease-free BSA)

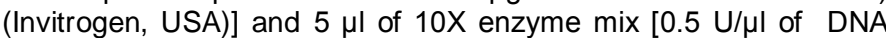
polymerase $1,0.007 \mathrm{U} / \mu \mathrm{l}$ of DNase $1.50 \mathrm{mM}$ of Tris- $\mathrm{HCl} \mathrm{pH} 7.5,5$ $\mathrm{mM}$ of magnesium chloride, $0.1 \mathrm{mM}$ of phenylmethylsulfonyl fluoride, $5 \%(\mathrm{v} / \mathrm{v})$ of glycerol and $100 \mu \mathrm{g} / \mathrm{ml}$ of nuclease-free BSA) (Invitrogen, USA)] were combined in $0.2 \mathrm{ml} \mathrm{PCR}$ tubes on ice. The total volume was brought to $50 \mu \mathrm{l}$ with PCR water. The mixture was incubated at $16^{\circ} \mathrm{C}$ in a thermal cycler for 2 hand then held at $4^{\circ} \mathrm{C}$ for nick translation of DNA. To precipitate the nick translated DNA, the samples were transferred to $1.5 \mathrm{ml}$ micro-centrifuge tubes followed by the addition of $5 \mathrm{ul}$ of $3 \mathrm{M}$ sodium acetate, $(\mathrm{pH} 5.2), 110 \mu \mathrm{l}$ of $100 \%$ ethanol and incubation at -80 for $30 \mathrm{~min}$. After the incubation, the DNA was pelleted by centrifugation at $14000 \mathrm{rpm}$ for 30 minat $4^{\circ} \mathrm{C}$. Then, the pellets were resuspended with $400 \mu \mathrm{l}$ of $70 \%$ ethanol. For more purification, the above steps were repeated once and the pellets were dried with a vacuum centrifuge for $10 \mathrm{~min}$. Finally, the purified nick-translated DNA was resuspended with $100 \mu \mathrm{l} 1 \mathrm{x}$ hybridization buffer.

\section{Microarray slide pre-hybridization preparation}

Microarray slides were prepared by immersing them in $50 \mathrm{ml}$ of $1 \%$ BSA blocking solution in a Coplin staining jar followed by incubation at room temperature for $10 \mathrm{~min}$, with shaking at $80 \mathrm{rpm}$ to eliminate bubbles on the slide surface. The slides were rinsed 20 times in double de-ionized after which their back and edges were wiped with a Kimwipe and spin dried with slide centrifuge for 15 seconds.

\section{Sample application/hybridization}

The nick translated gDNA was boiled for $3 \mathrm{~min}$, chilled on ice and briefly vortexed for $15 \mathrm{~s}$. Then, the microarray slides were placed on a humidified chamber $(200 \mu \mathrm{l}$ tip box and lid with de-ionized water covering the bottom of the box) and $45 \mu \mathrm{l}$ of the gDNA sample was placed in each well ( 2 wells per nick translated gDNA sample) on the microarray slide. The droplets were carefully spread to fully cover the well without touching the slide surface with the pipette. Carefully, the slide was sealed (face-up and frosted end toward the cap) in a hybridization chamber ( $50 \mathrm{ml}$ conical tube with filter paper moistened with $1 \mathrm{x}$ hybridization buffer). The slide was placed on top of the filter paper in the hybridization chamber without allowing the damp filter paper to touch the wells. The hybridization chamber was placed in a rack and lead weight on top of the rack, then the rack was submerged in the $55^{\circ} \mathrm{C}$ water bath. Finally, the sample DNA was allowed to hybridize with the probes on the array for $16 \mathrm{~h}$.

\section{Post-hybridization stringency washes}

After hybridization, the slides were removed from the hybridization chamber with forceps and excess hybridization solution was aspirated off the slides. Then, the slides were completely immersed (frosted end up) in a $55^{\circ} \mathrm{C}$ pre-warmed low stringency array wash solution (1X SSC, $0.2 \%$ SDS) contained in a Coplin jar. The above procedure was repeated in medium stringency (0.1XSSC, $0.2 \%$ SDS) and high stringency (0.1XSSC) array wash solutions respectively. At each time, the slides were washed for $4 \mathrm{~min}$ at room temperature on an Orbital shaker at $80 \mathrm{rpm}$. After the stringency washes, the slides were transferred to a horizontal staining jar that contains enough TNT buffer to cover the slide and were shaken for $1 \mathrm{~min}$ at $80 \mathrm{rpm}$ at room temperature to remove the stringency wash buffers. This TNT buffer washing was repeated three times.

\section{Microarray development}

For the following applications, $45 \mu$ of each solution was added directly to each well. The slides were gently tapped to distribute the reagent over the full well surface without allowing the reagents to cross over to other wells. The slides were spin-dried for $5 \mathrm{~s}$ using a slide centrifuge followed by incubation with 1:100 StreptvadinHorseredish peroxidase (SA-HRP) in TNB for $30 \mathrm{~min}$. After the incubation, the slides were washed 3 times for 1 min each in horizontal staining jars at $80 \mathrm{rpm}$ shaking. The above procedure was repeated with 10\% FES, 2XSSC; 1:50 BioT, 1xAmp Dil; and 1:500 SA-Alexa 555, 1XSSC, 5X Den. This last incubation was done for 1 $\mathrm{h}$ in the dark. All incubation were done at room temperature in a humidified chamber (made from a covered tip box with $\sim 10 \mathrm{ml} \mathrm{PCR}$ water in the bottom). At the end of these development reactions, the slides were spin-dried for $15 \mathrm{~s}$ using the slide centrifuge and were stored in the dark prior to scanning.

\section{Scanning/imaging of slides}

After hybridization and development, slides were scanned or imaged by standard DNA microarray slide scanners or imagers. The florescence marker used in this experiment (Alexa555) has an optimal excitation wavelength of $555 \mathrm{~nm}$ and emission wavelength of $565 \mathrm{~nm}$. The scanner/imager we used (Applied Precision array WoRx scanner) had a white light source and an emission filter for Cy3 that functions well for Alex555. We used an excitation wavelength of $540 \mathrm{~nm}$ (25 nm bandwidth) and an emission wave-length of $595 \mathrm{~nm}$ ( $50 \mathrm{~nm}$ bandwidth).

There were five pairs of Teflon-masked wells on each slide, with each well containing a full array and our normal protocol calls for two wells to be hybridized to the same sample. Within each well, there were two spots per probe so in effect there were four individual probe-target hybridizations ( 2 wells total). Each full array has dimensions of 22 horizontal and 20 vertical spots. The distance between spots is approximately $250 \mu \mathrm{m}$. 


\section{RESULTS}

\section{Antimicrobial resistance genes for microarray construction}

Ninety (90) antimicrobial resistance genes oligonucleotide probes were employed in the microarray; they include 21 aminoglycoside resistance genes, aac(3)-ld, aac(3)-III, aac(3)-Iva, aac(6')-Ib, aac(6')-IIa, aacC2, aacCA5, aadA1, aadA2, aadA21, aadA5, aadA7, aadB, aadE, aph(3)-la, aph(3)-Ila, aphA7, aphD, AphE, strA and strB; 21 beta-lactam resistance genes, blaACC-01, bla-CMY-2, blaCTX-M-1, blaCTX-M-12, blaCTX-M-15, blaCTX-M-2, blaCTX-M-8, blaDHA-1, blaFOX-2, blalMP-2, blaKPC-3, blaMIR, blaOXA-1, blaOXA-2, blaOXA-7, blaOXY-K1, blaPSE-1, blaPSE-4, blaROB-1, blaSHV-37, and TEM1; 10 chloramphenicol resistance genes, cat4, catB2, catB3, catB8, catl, catll, catP, cmlA, cm/B, and floR; 2 integrase genes, int/1, and intl2, 4 qinolone resistance genes, qac delta $E$, qnrA1, qnrB, and qnrS; 11 trimethoprim resistance genes, dfrA1, dfrA14, dfrA16, dfrA21, dhfrll, dhfrV, dhfrVI, dhfrVII, dhfrXII, dhfrXIII, and dhfrXV; 3 sulfonamide resistance genes, Sul1, Sul2, and sul3; and 18 tetracycline resistance genes, $\operatorname{tet}(C)$, tet $(Y)$, Tet30, TetA, tetB, TetD, TetE, tetG, TetH, TetJ, TetK, TetM, TetQ, TetS, TetT, TetV, TetW and TetX.

The sequence identity of each gene was compared with GenBank sequences, therefore, all the 90 genes were used to construct the DNA microarray; biotin was used as the positive control and 16s rDNA as orientation.

To determine the specificity of microarray hybridization, all of the labeled genes probes were hybridized to the microarray. In most cases, there was a one-to-one correspondence for hybridization signal to respective target, orientation gene, and positive control gene spots. There was minor cross-hybridization between some genes and they were marked as abnormal during analysis, thus these genes are not included in the net results shown here.

\section{Detection of antimicrobial resistance gene with microarray}

The antimicrobial resistance genes of $60 \mathrm{E}$. coli isolates were tested with the microarray. Considering resistance according to class of antibiotics, the following resistance genes were most commonly present in the isolates: for aminoglycoside, strA was most prevalent $(65.0 \%)$; the isolates from the south-east harbored this gene most $(88.2 \%)$, among the human isolates (Table 1). In betalactam, bla-CMY-2 was most frequent in the isolates, $38(63.3 \%)$ and $28(70 \%$ ) (Table 2$)$.

However, analysis of isolates from different geopolitical zones shows that TEM1 occurred highest among the individual zones with $14(82.4 \%)$ in south-east. The analysis of chloramphenicol resistance genes encountered in this study indicated that 26 isolates, (43.3\%) harbored this gene. Integrase gene, int1 was most prevalent in the sample sources with 35 isolates (58.3\%) harboring the gene in human specimens. The most detected qinolone resistance gene was qnrA1; 25 isolate (41.7\%) (Table 3).

Table 4 shows the prevalent of trimethoprim and sulfonamide resistance genes detected in this study. dfrA16 was most frequent in the specimens; 17 isolates (28.3\%). For sulfonamide resistance genes, $35(58.3 \%)$ of the isolates, harbored Sul2 at highest rate. Tetra-cycline resistance gene profile observed in this study indicates that TetA was most frequent in the sample sources with 36 isolates $(60 \%)$ of human specimens bearing this gene (Table 5). The TetM (one isolate from north-north), TetQ (10 isolates $16.7 \%$ ) and TetW (one isolate from northcentral) were detected in this study. Figure 1 is a representative of the microphotograph of microarrays hybridized with genomic DNAs of E.coli isolates.

\section{DISCUSSION}

The microarray was designed with oligonucleotides of 50100 bases. This enabled us to find consensus sequences within a family of genes sharing high DNA identities (Barlow et al., 2008). The consensus sequences allow for identification of the few different bases which distin-guish these genes and also indicate which family they belong.

Two different oligonucleotides probes were chosen for each resistance gene; the use of two different oligonucleotides for the detection of each resistance gene has the advantage of increased specificity and sensitivity of the method. Lack of sensitivity was found in three out of 60 isolates genotyped by microarray: ( $\mathrm{PH} 18$, south-south, JA10, north-north and LA13, south-west). This demonstrated that, the oligonucleotide was effectively spotted on the microarray and indicated that the detection of the probe depend on the labeling procedure. The hybridization analysis using genomic DNAs of our isolates enabled verification of the sensitivity of the oligonucleotide targets and identification of 94 resistance genes.

\section{The resistance gene array allowed us to quickly characterize a collection of resistance genes in $E$. coli of diverse origin}

For example, the high tetracycline resistance observed in this study could be explained by the presence of variety of tetracycline resistance genes $(\operatorname{tet}(C)$, tet $(Y)$, Tet30, TetA, tetB, TetD, TetE, tetG, TetH, TetJ, TetK, TetM, TetQ, TetS, TetT, TetV, TetW and TetX), known to be involved in resistance to tetracycline antibiotic (Guay, 2008). This is, to our knowledge, the first report of the detection of aph(3')-III, and ant(6)-la genes in a E. coli strain, suggesting the presence of a Tn5405-like structure. Transposon Tn5405 carries an ant(6')-la-sat4aph (3')-III cluster which is widespread among Salmonella and Shigella and might have been transferred from one 
Table 1. The prevalence of aminoglycosides resistance genes in human $E$. coli isolates from Nigeria.

\begin{tabular}{lcccccc}
\hline Gene & \multicolumn{7}{c}{ Source of samples } \\
\cline { 2 - 7 } & $\begin{array}{c}\text { South - East } \\
(\mathbf{N}=\mathbf{1 7})\end{array}$ & $\begin{array}{c}\text { South South } \\
(\mathbf{N}=\mathbf{1 3})\end{array}$ & $\begin{array}{c}\text { South -West } \\
(\mathbf{N}=\mathbf{1 3})\end{array}$ & $\begin{array}{c}\text { North - North } \\
(\mathbf{N}=13)\end{array}$ & $\begin{array}{c}\text { North-Cnetral } \\
(\mathbf{N}=\mathbf{4})\end{array}$ & $\begin{array}{c}\text { Total } \\
(\mathbf{N}=60)\end{array}$ \\
\hline aac(3)-Id & $01(5.9)$ & 00 & 00 & 00 & $03(75)$ & $04(4.7)$ \\
aac(3)-III & $03(17.6)$ & $06(46.2)$ & $07(53.8)$ & 00 & 00 & $16(26.7)$ \\
aac(3)-IVa & 00 & $01(7.7)$ & 00 & 00 & 00 & $01(1.7)$ \\
aac(6')-Ib & 00 & $03(23.1)$ & $03(23.1)$ & 00 & $01(25)$ & $07(11.7)$ \\
aac(6')-Ila & $01(5.9)$ & $01(7.7)$ & 00 & $01(7.7)$ & 00 & $03(5.0)$ \\
aacC2 & $01(5.9)$ & $03(23.1)$ & $03(23.1)$ & 00 & 00 & $07(11.7)$ \\
aacCA5 & $07(41.2)$ & 00 & $01(7.7)$ & $01(7.7)$ & 00 & $09(15.0)$ \\
aadA1 & $13(76.5)$ & $02(15.4)$ & $05(38.5)$ & $02(15.4)$ & $01(25)$ & $23(38.3)$ \\
aadA2 & $13(76.5)$ & $01(7.7)$ & $06(46.2)$ & $03(23.1)$ & $01(25)$ & $24(40.0)$ \\
aadA21 & $13(76.5)$ & $01(7.7)$ & $05(38.5)$ & $03(23.1)$ & $01(25)$ & $23(38.3)$ \\
aadA5 & $04(23.5)$ & 00 & $04(30.8)$ & 00 & $03(75)$ & $11(18.3)$ \\
aadA7 & 00 & $01(7.7)$ & 00 & 00 & 00 & $01(1.7)$ \\
aadB & 00 & 00 & 00 & 00 & $01(25)$ & $01(1.7)$ \\
aadE & $08(47.1)$ & $06(46.2)$ & $07(53.9)$ & $08(61.5)$ & $04(100)$ & $33(55.0)$ \\
aph(3)-la & 00 & 00 & 00 & 00 & 00 & 00 \\
aph(3)-Ila & $01(5.9)$ & $01(7.7)$ & $04(30.8)$ & $01(7.7)$ & $02(50)$ & $09(15.0)$ \\
aphA7 & 00 & $01(7.7)$ & $01(7.7)$ & $01(7.7)$ & $01(25)$ & $04(6.7)$ \\
aphD & $06(35.3)$ & $04(30.8)$ & $02(15.4)$ & $02(15.4)$ & $03(75)$ & $17(28.3)$ \\
AphE & 00 & 00 & $02(15.3)$ & $01(7.7)$ & $01(25)$ & $04(4.70$ \\
strA & $15(88.2)$ & $07(53.8)$ & $07(53.8)$ & $06(46.2)$ & $04(100)$ & $39(65.0)$ \\
strB & $15(88.2)$ & $03(23.1)$ & $06(46.2)$ & $03(23.1)$ & $02(25)$ & $19(48.3)$ \\
\hline
\end{tabular}

$\mathrm{N}=$ Number of isolates hybridized.

Table 2. The prevalence of Beta-lactam resistance genes in human E. coli isolates from Nigeria.

\begin{tabular}{|c|c|c|c|c|c|c|}
\hline \multirow[b]{2}{*}{ Gene } & \multicolumn{6}{|c|}{ Source of samples } \\
\hline & $\begin{array}{c}\text { South - East } \\
(\mathrm{N}=17)\end{array}$ & $\begin{array}{l}\text { South South } \\
(N=13)\end{array}$ & $\begin{array}{c}\text { South -West } \\
(N=13)\end{array}$ & $\begin{array}{c}\text { North - North } \\
(\mathrm{N}=13)\end{array}$ & $\begin{array}{c}\text { North-Central } \\
(\mathrm{N}=4)\end{array}$ & $\begin{array}{l}\text { Total } \\
(\mathrm{N}=60)\end{array}$ \\
\hline blaACC-01 & $01(5.9)$ & 00 & 00 & $02(15.4)$ & 00 & $03(5.0)$ \\
\hline bla-CMY-2 & $12(70.6)$ & $07(53.8)$ & $06(46.2)$ & $09(69.2)$ & $04(100)$ & $38(63.3)$ \\
\hline blaCTX-M-1 & 05(29.4) & 00 & $02(15.4)$ & 00 & $04(100)$ & 11(18.3) \\
\hline blaCTX-M-12 & 00 & 00 & 00 & 00 & 00 & 00 \\
\hline blaCTX-M-15 & $05(29.4)$ & $01(7.7)$ & 00 & $01(7.7)$ & $02(50)$ & $09(15)$ \\
\hline blaCTX-M-2 & 00 & 00 & 00 & $01(7.7)$ & 00 & $01(1.7)$ \\
\hline blaCTX-M-8 & $04(23.5)$ & 00 & 00 & 00 & $01(25)$ & $06(8.3)$ \\
\hline blaDHA-1 & 00 & 00 & 00 & 00 & 00 & 00 \\
\hline blaFOX-2 & 00 & 01(7.7) & 00 & 00 & 00 & $01(1.7)$ \\
\hline blalMP-2 & 00 & 00 & 00 & 00 & 00 & 00 \\
\hline blaKPC-3 & $12(70.6)$ & $03(20.1)$ & 06(46.2) & $01(7.7)$ & $03(75)$ & $25(41.7)$ \\
\hline blaMIR & 00 & $01(7.7)$ & 00 & $01(7.7)$ & $01(25)$ & $03(5.0)$ \\
\hline blaOXA-1 & $04(23.5)$ & $03(20.1)$ & $02(15.4)$ & $02(15.4)$ & $01(25)$ & $12(20)$ \\
\hline blaOXA-2 & $01(5.9)$ & 00 & 00 & 00 & 00 & $01(1.7)$ \\
\hline blaOXA-7 & 00 & $01(7.7)$ & 00 & 00 & 00 & 01(1.7) \\
\hline blaOXY-K1 & 00 & $01(7.7)$ & 00 & 00 & 00 & $01(1.7)$ \\
\hline blaPSE-1 & $01(5.9)$ & 00 & 00 & 00 & 00 & $01(1.7)$ \\
\hline blaPSE-4 & $10(58.8)$ & $03(20.1)$ & $07(53.8)$ & $02(15.4)$ & $04(100)$ & $26(43.3)$ \\
\hline blaROB-1 & 00 & $01(7.7)$ & $01(7.7)$ & 00 & 00 & $02(3.3)$ \\
\hline blaSHV-37 & $02(11.8)$ & 00 & 00 & $01(7.7)$ & $01(25)$ & $04(6.7)$ \\
\hline TEM1 & $14(82.4)$ & $06(46.2)$ & $08(61.5)$ & $06(46.2)$ & $02(50)$ & $36(60)$ \\
\hline
\end{tabular}

$\mathrm{N}=$ Number of isolates hybridized. 
Table 3. The prevalence of chloramphenicol and qinolone resistance genes in human E. coli Isolates from Nigeria.

\begin{tabular}{lcccccc}
\hline Gene & \multicolumn{7}{c}{ Source of samples } \\
\cline { 2 - 7 } & $\begin{array}{c}\text { South - East } \\
(\mathbf{N}=\mathbf{1 7})\end{array}$ & $\begin{array}{c}\text { South South } \\
(\mathbf{N}=\mathbf{1 3})\end{array}$ & $\begin{array}{c}\text { South -West } \\
(\mathbf{N}=\mathbf{1 3})\end{array}$ & $\begin{array}{c}\text { North - North } \\
(\mathbf{N}=\mathbf{1 3})\end{array}$ & $\begin{array}{c}\text { North-Central } \\
\mathbf{( N = 4 )}\end{array}$ & $\begin{array}{c}\text { Total } \\
\mathbf{( N = 6 0 )}\end{array}$ \\
\hline cat4 & $13(76.5)$ & $01(7.7)$ & $02(15.4)$ & 00 & $01(25)$ & $17(28.3)$ \\
catB2 & 00 & $02(15.4)$ & $01(7.7)$ & 00 & 00 & $03(5.0)$ \\
catB3 & 00 & $03(23.1)$ & $02(15.4)$ & 00 & 00 & $05(8.3)$ \\
catB8 & $02(11.8)$ & $03(23.1)$ & $03(23.1)$ & 00 & $01(25)$ & $09(15.0)$ \\
catl & $12(70.6)$ & $01(7.7)$ & $02(15.4)$ & 00 & $01(25)$ & \\
catll & 00 & 00 & $01(7.7)$ & 00 & 00 & $01(1.7)$ \\
catP & 00 & 00 & 00 & 00 & $01(25)$ & $01(1.7)$ \\
cmIA & 00 & 00 & $01(7.7)$ & $04(30.8)$ & 00 & $05(8.3)$ \\
cmIB & $05(29.4)$ & 00 & $02(15.4)$ & $03(23.1)$ & 00 & $10(16.7)$ \\
floR & $07(41.2)$ & $03(23.1)$ & $07(53.8)$ & $05(38.5)$ & $04(100)$ & $26(43.3)$ \\
int/1 & $12(70.6)$ & $09(69.2)$ & $07(53.8)$ & $06(46.2)$ & $01(25)$ & $35(58.3)$ \\
intl2 & 00 & 00 & $02(15.4)$ & 00 & $02(50)$ & $04(6.7)$ \\
qac delta $E$ & $12(70.6)$ & $08(61.5)$ & $07(53.4)$ & $04(30.8)$ & $02(20)$ & $33(55)$ \\
qnrA1 & $08(47.1)$ & $03(23.1)$ & $07(53.4)$ & $03(23.1)$ & $04(100)$ & $25(41.7)$ \\
qnrB & 00 & $01(7.7)$ & $017.7)$ & 00 & 00 & $02(3.3)$ \\
qnrS & 00 & $01(7.7)$ & 00 & $01(7.7)$ & $01(25)$ & $03(5.0)$ \\
\hline
\end{tabular}

$\mathrm{N}=$ Number of isolates hybridized.

Table 4. The prevalence of trimethoprim and sulfonamide resistance genes in human E. coli isolates from Nigeria.

\begin{tabular}{lcccccc}
\hline Gene & \multicolumn{7}{c}{ Source of sample } \\
\cline { 2 - 6 } & $\begin{array}{c}\text { South - East } \\
(\mathbf{N}=17)\end{array}$ & $\begin{array}{c}\text { South - East } \\
(\mathbf{N}=\mathbf{1 7})\end{array}$ & $\begin{array}{c}\text { South - East } \\
(\mathbf{N}=17)\end{array}$ & $\begin{array}{c}\text { South - East } \\
(\mathbf{N}=\mathbf{1 7})\end{array}$ & $\begin{array}{c}\text { South - East } \\
(\mathbf{N}=17)\end{array}$ & $\begin{array}{c}\text { South - East } \\
(\mathbf{N}=\mathbf{1 7})\end{array}$ \\
\hline dfrA1 & $10(58.8)$ & 00 & $03(23.1)$ & 00 & $01(25)$ & $14(23.3)$ \\
dfrA14 & $02(11.8)$ & $04(30.8)$ & $03(23.1)$ & $04(30.8)$ & $02(50)$ & $15(25)$ \\
dfrA16 & $13(76.5)$ & 00 & $01(7.7)$ & $02(15.4)$ & $01(25)$ & $17(28.3)$ \\
dfrA21 & 00 & 00 & 00 & $02(15.4)$ & 00 & $02(3.3)$ \\
dhfrll & 00 & 00 & 00 & 00 & 00 & 00 \\
dhfrV & $01(5.9)$ & $03(23.1)$ & $02(15.4)$ & $04(30.8)$ & $01(25)$ & $11(18.3)$ \\
dhfrVI & $03(17.6)$ & 00 & $01(7.7)$ & $01(7.7)$ & 00 & $05(8.3)$ \\
dhfrVII & $03(17.6)$ & $04(30.8)$ & $01(7.7)$ & $01(7.7)$ & $01(25)$ & $10(16.7)$ \\
dhfrXII & 00 & 00 & $01(7.7)$ & $04(30.8)$ & 00 & $05(8.3)$ \\
dhfrXIII & 00 & 00 & $01(7.7)$ & $04(30.8)$ & 00 & $05(8.3)$ \\
dhfrXV & 00 & 00 & $0197.7)$ & 00 & 00 & $1(1.7)$ \\
Sul1 & $13(76.5)$ & $03(23.1)$ & $05(38.5)$ & $01(7.7)$ & 00 & $22(36.7)$ \\
Sul2 & $14(82.4)$ & $07(53.8)$ & $07(53.8)$ & $05(38.5)$ & $02(50)$ & $35(58.3)$ \\
sul3 & 00 & 00 & $02(15.4)$ & $04(30.8)$ & 00 & $06(10)$ \\
\hline
\end{tabular}

$\mathrm{N}=$ Number of isolates hybridized

of these species to E.coli. This demonstrate the efficiency of this technology to rapidly characterize antibiotic resistance genes in strains whose resistance genotype was completely unknown. Furthermore, automation of the hybridization procedures is conceivable, since all the hybridization steps are performed in the same tube. The microarray technology will then facilitate and speed the analysis of antibiotic resistance genes.

The microarrays have the particular advantage of detec- ting the presence of antibiotic resistance genes that are not phenotypically expressed in vitro. We have compared this microarray assay for the detection of antibiotic resistance genes with traditional phenotypic methods for the determination of antibiotic susceptibility. Overall, we found that, the discrepancies between the microarray results and the disk diffusion results are not significant ( 3 out of 60 isolates) and were mainly due to the phenoltypically susceptible, but resistance gene-positive isola- 
Table 5. The prevalence of tetracycline resistance genes in human E. coli Isolates from Nigeria.

\begin{tabular}{|c|c|c|c|c|c|c|}
\hline \multirow[b]{2}{*}{ Gene } & \multicolumn{6}{|c|}{ Sources of sample } \\
\hline & $\begin{array}{c}\text { South - East } \\
(N=17)\end{array}$ & $\begin{array}{c}\text { South - East } \\
(\mathrm{N}=17)\end{array}$ & $\begin{array}{c}\text { South - East } \\
(\mathrm{N}=17)\end{array}$ & $\begin{array}{c}\text { South - East } \\
(\mathrm{N}=17)\end{array}$ & $\begin{array}{c}\text { South - East } \\
(\mathrm{N}=17)\end{array}$ & $\begin{array}{c}\text { South - Eas } \\
(\mathrm{N}=17)\end{array}$ \\
\hline $\operatorname{tet}(C)$ & 05(29.4) & $02(15.4)$ & $03(23.1)$ & $02(15.4)$ & $03(75)$ & $15(25)$ \\
\hline $\operatorname{tet}(Y)$ & 05(29.4) & $03(23.1)$ & $02(15.4)$ & $02(15.4)$ & $01(25)$ & $13(21.7)$ \\
\hline Tet30 & $05(29.4)$ & $03(23.1)$ & $02(15.4)$ & $01(7.7)$ & $02(50)$ & $13(21.7)$ \\
\hline TetA & $12(70.6)$ & $07(58.3)$ & $06(46.2)$ & $07(58.3)$ & $04(100)$ & $36(60)$ \\
\hline tetB & $14(82.4)$ & $07(58.3)$ & $03(23.1)$ & $01(7.7)$ & $01(25)$ & $26(43.3)$ \\
\hline$T e t D$ & $13(76.5)$ & $03(23.1)$ & $03(23.1)$ & $01(7.7)$ & $04(100)$ & $24(40)$ \\
\hline TetE & $12(70.6)$ & 00 & $02(15.4)$ & 00 & $01(25)$ & $15(25)$ \\
\hline $\operatorname{tet} G$ & $06(35.3)$ & $02(23.1)$ & $02(15.4)$ & $01(7.7)$ & 00 & $11(18.3)$ \\
\hline TetH & $05(29.4)$ & $05(38.5)$ & $01(7.7)$ & $02(15.4)$ & $01(25)$ & $14(23.3)$ \\
\hline TetJ & $05(29.4)$ & $02(23.1)$ & $03(23.1)$ & $06(46.2)$ & $03(75)$ & $19(31.7)$ \\
\hline TetK & $05(29.4)$ & $05(38.5)$ & $02(15.4)$ & $02(15.4)$ & $01(25)$ & $15(25)$ \\
\hline TetM & 00 & 00 & 00 & $01(7.7)$ & 00 & $01(1.7)$ \\
\hline TetQ & $02(11.8)$ & $05(38.5)$ & 00 & $02(15.4)$ & $01(25)$ & $10(16.7)$ \\
\hline TetS & $05(29.4)$ & 00 & $01(7.7)$ & $01(7.7)$ & 00 & $07(11.7)$ \\
\hline TetT & 00 & 00 & 00 & 00 & $01(25)$ & $01(1.7)$ \\
\hline TetV & 00 & 00 & 00 & 00 & 00 & 00 \\
\hline TetW & 00 & 00 & 00 & 00 & $01(25)$ & $01(1.7)$ \\
\hline TetX & 00 & 00 & 00 & $01(7.7)$ & $01(25)$ & $02(3.3)$ \\
\hline
\end{tabular}

$\mathrm{N}=$ Number of isolates hybridized.

isolates. For example, we encountered cephalosporin sus-ceptible, but bla-CMY-2-positive strains $(n=3)$, presumably because of the known heterogeneous expression of bla-CMY-2 gene in enterobacteriaceae in vitro (Call et al., 2003). More examples are seen in the following isolates where microarray detected genes that were not phenotypically expressed by the isolates. $\mathrm{PH} 11$ South-south (aadE, bla-CMY-2); KD 4, JA3 -North-north (floR, strB); LA 4- South-west (aadE, bla-CMY-2, blaPSE4, floR, qac delta $E$, qnrA1, TetJ-); For more frequently encountered gentamicin-susceptible but aac(6')-le-aph $\left(2^{m \prime}\right)$-positive isolates, the discrepancy in genotype and phenoltype might be attributed to the so-called silent antibiotic resistance gene that might become activated to express the resistance (Martineau et al., 2000a), and their presence may also facilitate the spread to other bacteria. From a clinical perspective, a susceptible strain harboring but not expressing an antibiotic resistance gene should be regarded as potentially resistant to that antibiotic (Martineau et al., 2000b). Thus, detection of the discrepancies between the presence of the resistance gene and the phenotypic susceptibility (false-positive) is important for physicians to guide prescription of appropriate functional antibiotic therapy so as to control the spread of the resistance due to antibiotic selection.

Furthermore, there are also discrepancies between the absence of the antibiotic gene test on the microarray and the phenotypic resistance (false negative). This was observed in isolates PH 18-South-south (Am-C-Sxt-T); LA 13-Southwest (Am-C-Sxt-S-T-Amc-Nal); LA 15-South-west (Am-
Sxt-S-T); Resistance was phenotypically observed against the antibiotics written against each of the isolates but the genes were not detected by the microarray. This could be attributed by the non inclusion of the oligo-nucleotide probes encoding theses genes in the construction of the microarray or the genes encoding the resistance are novel. However, more research is needed in this area before conclusion can be established.

The most common mechanism of cephalosporin resistance is through production of beta-lactamases. Broadspectrum cephalosporins, like cephalothin, have increased ring stability against some beta-lactamases but are susceptible to cephamycinases (Call et al., 2003). Cephamycinase (bla-CMY-2) share extensive homology to chromosomal ampC beta-lactamases. The bla-CMY-2 gene is closely related to the chromosomal $a m p C$ of Citrobacter freundii. Cephalothin resistance in $E$. coli is typically due to the presence of the bla-CMY-2 gene (Call et al., 2003). Our findings support this, as the bla-CMY-2 gene was found in $63.3 \%$ of human isolates in this study. Antibiotic-resistant bacteria today are present in a large variety of ecological niches such as hospitals, the environment, and food.

In conclusion, the DNA microarray presented in this study has been shown to be an efficient prototype that allows for rapid screening of resistance genes in E. coli. This technology should rapidly find application in surveillance programs of antibiotic resistance genes, industry, and research in order to limit the emergence and spread of antibiotic resistance genes and extend the therapeutic 


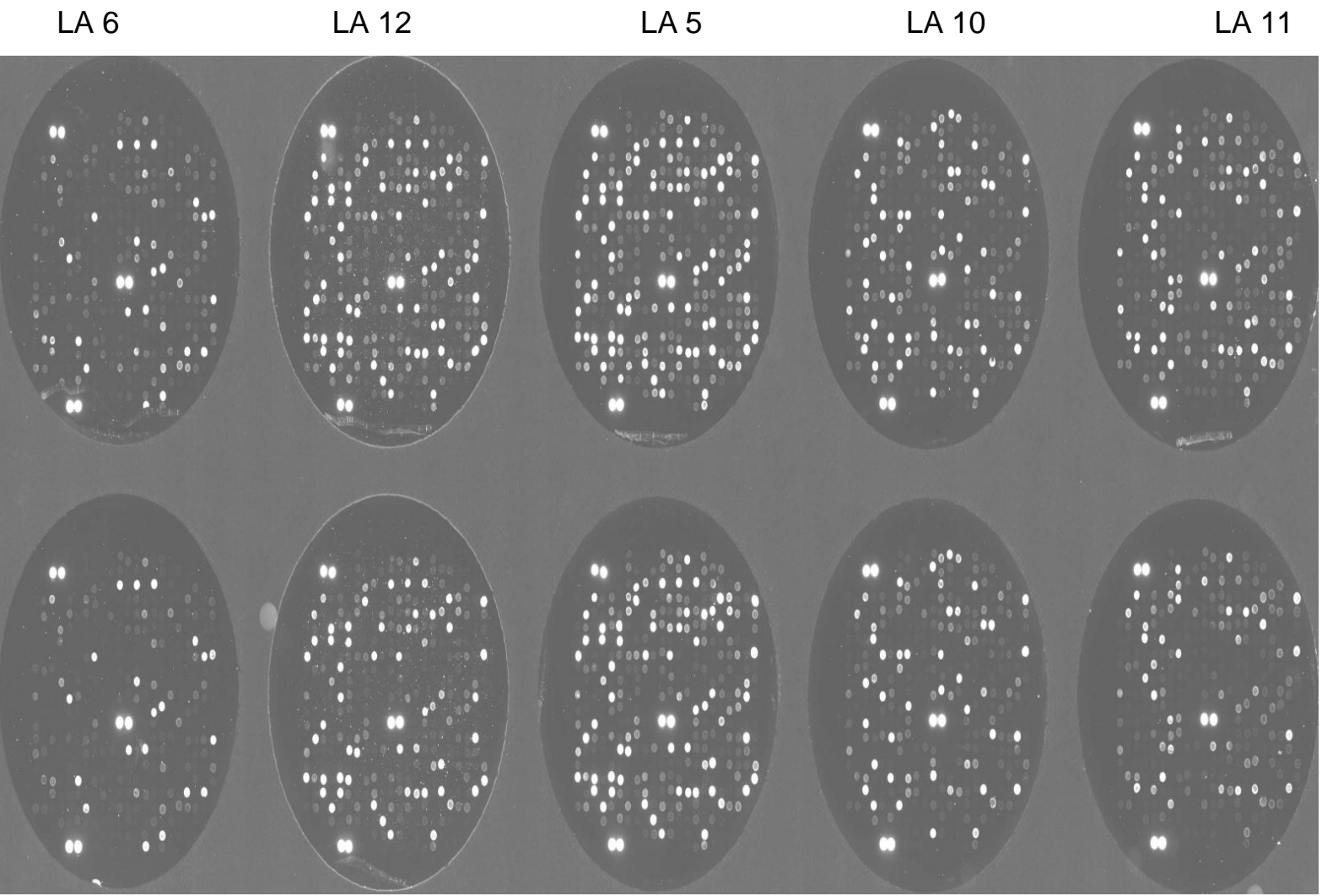

Figure 1. Microphotograph of microarrays hybridized with genomic DNAs of E.coli lsolates from South-West Nigeria.

\section{action of existing drugs.}

\section{REFERENCES}

Barlow M, Reik RA, Jacobs SD, Medina M, and Meyer MP. (2008). High rate of mobilization for bla

Call DR, Chandler DP, Brockman F (2001). Fabrication of DNA microarrays using unmodified oligonucleotide probes. BioTech. 30:368-379.

Call DR, Bakko MK, Krug MJ, Roberts MC (2003a). Identifying antimicrobial resistance genes with DNA microarrays. Antimicrob. Agents Chemother. 47:3290-3295.

Call DR, Borucki MK, Loge FJ (2003b). Detection of bacterial pathogens in environmental samples using DNA microarrays. J. Microbiol. Methods 53:235-243.

Cheesbrough M (2000). District Laboratory Practice in Tropical Countries, Part 2. Cambridge University Press, Cambridge, UK; pp.434.

Cassone M, Marco MD, Francesco I, Marco RO, Gian MR, Gianni P (2006). DNA Microarray for Detection of Macrolides Resistance Genes. Antimicrob. Agents Chemother. pp. 2038-2041.

Clinical Laboratory Standards Institute (2006). Performance standards for Antimicrobial susceptibility testing. National committee for clinical laboratory standards, Wayne pa.

Martineau F, Picard FJ, Grenier L, Roy PH, Ouellette M, Bergeron MG (2000a). Multiplex PCR assays for the detection of clinically relevant antibiotic resistance genes in Staphylococci isolated from patients infected after cardiac surgery. J. Antimicrob. Chemother. 46:527-533.

Martineau F, Picard FJ, Grenier L, Roy PH, Ouellette M, Bergeron MG (2000b). Correlation between the resistance genotype determined by multiplex PCR assays and the antibiotic susceptibility patterns of
Staphylococcus aureus and Staphylococcus epidermidis. Antimicrob. Agents Chemother. 44:231-238.

Murakami S, Nakashima R, Yamashita E, Yamaguchi A (2002).Crystal structure of bacterial multidrug efflux transporter AcrB. Nature 419:587-593.

Nsofor CA, Iroegbu CU (2013) Antibiotic Resistance Profile of Escherichia coli Isolated from Five Major Geopolitical Zones of Nigeria. J. Bacteriol. Res. 5(3):29-34.

Panicker G, Call DR, Krug MJ, Bej AK (2004). Detection of Pathogenic Vibrio spp. in Shellfish by Using Multiplex PCR and DNA Microarrays. Appl. Environ. Microbiol. pp.7436-7444.

Perreten VL, Vorlet-Fawer P, Slickers R, Ehricht PK, Frey J (2005). Microarray-based detection of 90 antibiotic resistance genes of grampositive bacteria. J. Clin. Microbiol. 43:2291-2302.

Peterson G, Jianfa B, Nagaraja TG, Sanjeev N (2010). Diagnostic microarray for human and animal bacterial diseases and their virulence and antimicrobial resistance genes. J. Microbiol. Methods 80:223-230.

Ye Y, He X, Szewczyk P, Nguyen T, Chang G (2006). Structure of the multidrug transporter EmrD from Escherichia coli. Sci. 312:741-744. 